\title{
The usefulness of twenty-four molecular markers in predicting treatment outcome with combination therapy of amodiaquine plus sulphadoxine-pyrimethamine against falciparum malaria in Papua New Guinea
}

\author{
Jutta Marfurt 1,3, Ivo Müller², Albert Sie ${ }^{2}$, Olive Oa ${ }^{2,4}$, John C Reeder ${ }^{2,5}$, \\ Thomas A Smith ${ }^{1,6}$, Hans-Peter Beck ${ }^{1,7}$ and Blaise Genton*1,8
}

\begin{abstract}
Address: ${ }^{2}$ Swiss Tropical Institute, Socinstrasse 57, P.O. Box, CH-4002 Basel, Switzerland, 2Papua New Guinea Institute of Medical Research, Goroka, P.O. Box 60, EHP 441, Papua New Guinea, ${ }^{3}$ Menzies School of Health Research, P.O. Box 41096, Casuarina, Darwin, NT 0811, Australia, ${ }^{4}$ Papua New Guinea Institute of Medical Research, Maprik, P.O. Box 400, ESP 533, Papua New Guinea, ${ }^{5}$ International Health Research Strategy, Burnet Institute for Medical Research and Public Health, P.O. Box 2284, Melbourne VIC 2001, Australia, ${ }^{6}$ Swiss Tropical Institute, Department of Public Health and Epidemiology, Socinstrasse 57, P.O. Box, CH-4002 Basel, Switzerland, ${ }^{7}$ Swiss Tropical Institute, Department of Medical Parasitology and Infection Biology, Socinstrasse 57, P.O. Box, CH-4002 Basel, Switzerland and ${ }^{8}$ Ifakara Health Research \& Development Centre, P.O. Box 78373, Dar es Salaam, Tanzania

Email: Jutta Marfurt - jutta.marfurt@gmail.com; Ivo Müller - pngimr_ivo@datec.net.pg; Albert Sie - Albert.Sie@pngimr.org.pg; Olive Oa - Olive.Oa@pngimr.org.pg; John C Reeder - jreeder@burnet.edu.au; Thomas A Smith - Thomas-A.Smith@unibas.ch; HansPeter Beck - Hans-Peter.Beck@unibas.ch; Blaise Genton* - Blaise.Genton@unibas.ch

* Corresponding author
\end{abstract}

Published: 19 April 2008

Malaria Journal 2008, 7:61 doi:10.1 I86/|475-2875-7-6I

This article is available from: http://www.malariajournal.com/content/7/I/6I

(C) 2008 Marfurt et al; licensee BioMed Central Ltd.

This is an Open Access article distributed under the terms of the Creative Commons Attribution License (http://creativecommons.org/licenses/by/2.0), which permits unrestricted use, distribution, and reproduction in any medium, provided the original work is properly cited.

\begin{abstract}
Background: In Papua New Guinea (PNG), combination therapy with amodiaquine (AQ) or chloroquine (CQ) plus sulphadoxine-pyrimethamine (SP) was introduced as first-line treatment against uncomplicated malaria in 2000.

Methods: We assessed in vivo treatment failure rates with AQ+SP in two different areas in PNG and twenty-four molecular drug resistance markers of Plasmodium falciparum were characterized in pretreatment samples. The aim of the study was to investigate the association between infecting genotype and treatment response in order to identify useful predictors of treatment failure with $A Q+S P$.

Results: In 2004, Day-28 treatment failure rates for AQ+SP were $29 \%$ in the Karimui and $19 \%$ in the South Wosera area, respectively. The strongest independent predictors for treatment failure with $A Q+S P$ were pfmdrI N86Y $(O R=7.87, p<0.01)$ and pfdhps A437G $(O R=3.44, p<0.01)$. Mutations found in CQ/AQ related markers pfcrt $\mathrm{K} 76 \mathrm{~T}, \mathrm{~A} 220 \mathrm{~S}, \mathrm{~N} 326 \mathrm{D}$, and $1356 \mathrm{~L}$ did not help to increase the predictive value, the most likely reason being that these mutations reached almost fixed levels. Though mutations in SP related markers pfdhfr SI $08 \mathrm{~N}$ and C59R were not associated with treatment failure, they increased the predictive value of pfdhps A437G. The difference in treatment failure rate in the two sites was reflected in the corresponding genetic profile of the parasite populations, with significant differences seen in the allele frequencies of mutant pfmdrl N86Y, pfmdrl YI84F, pfcrt A220S, and pfdhps A437G.

Conclusion: The study provides evidence for high levels of resistance to the combination regimen of $\mathrm{AQ}+\mathrm{SP}$ in PNG and indicates which of the many molecular markers analysed are useful for the monitoring of parasite resistance to combinations with $\mathrm{AQ}+\mathrm{SP}$.
\end{abstract}




\section{Background}

The effectiveness of the most widely used first-line antimalarials chloroquine (CQ) and sulphadoxine-pyrimethamine (SP) has been heavily compromised by the emergence and spread of Plasmodium falciparum resistance to these drugs. In order to improve treatment efficacy and to delay the development and spread of drug resistance, there is strong advocacy for combination therapy [1]. Though the combination of 4 -aminoquinolines or SP with artemisinin derivates is recommended, this option is expensive and several countries have taken an interim step and chose the inexpensive combination of amodiaquine (AQ) or CQ plus SP.

Monitoring of parasite resistance is essential in directing the rational use of antimalarials. Apart from studies assessing in vivo drug efficacy and in vitro drug sensitivity, molecular markers have been proposed as a means to monitor drug resistant malaria [2]. CQ resistance has been attributed to several mutations occurring in the P. falciparum chloroquine resistance transporter gene ( $p f c r t)$ and $P$. falciparum multidrug resistance gene 1 ( $p f m d r 1$ ). Correlation between molecular markers of CQ resistance and in vivo treatment outcome has been complex. Whereas several studies have shown the key role of $p f c r t$ K76T in conferring in vivo resistance to CQ [3,4], the relationship between phenotypic resistance and other $p f c r t$ polymorphisms (i.e., C72S/R, M74I/T, N75E/D/K/I，K76T/I/N, I77T，H97Q/L，A144F/T，L148I，L160Y，I194T，A220S， Q271E, N326S/D, I356V/T/L and R371T/I), which have been shown to be associated with CQ resistance in vitro, has been little studied in the field. Single-base changes in pfmdr1 N86Y, Y184F, S1034C, N1042D and D1246Y have been documented in CQ resistant laboratory strains, but a straightforward association of these polymorphisms with in vivo CQ resistance has been questioned by several authors $[5,6]$.

The accumulation of point mutations in $P$. falciparum dihydrofolate reductase ( $p f d h f r$ ) and dihydropteroate synthase ( $p f d h p s)$, two enzymes in the parasite's folate synthesis pathway, is associated with resistance to SP. Though the relationship between polymorphisms in these genes and resistance to SP has been shown in vitro, the correlation of different genotypes and clinical treatment outcome varies between different epidemiological settings. Whereas the triple mutation S108N+C59R+N51I in $p f d h f r$ has been found to be a good molecular marker for SP resistance by some authors [7-9], others did not confirm the usefulness of this combination of mutations $[10,11]$. The quintuple mutation pfdhfr S108N+C59R+N51I plus pfdhps A437G+K540E has been proposed as a useful indicator for monitoring SP resistance in Africa [12], in the Amazon region, the quintuple mutation pfdhfr S108N+N51I+I164L plus pfdhps A437G+K540E has been shown to be more useful [13]. More recently, several authors have found the double mutation $p f d h f r$ C59R plus pfdhps K540E to be sufficient to predict treatment failure in vivo [14-16]. The most likely reason for these conflicting reports is the fact that, apart from the infecting genotype, response to drug treatment is affected by many factors, such as host immunity, which is related to transmission intensity, and history of drug use in a given area $[10,17,18]$. As a consequence, the patterns as well as the predictive values of molecular drug resistance markers may vary between different geographical regions. Another problem is that most of the studies looked at only few markers, which does not allow comparing the respective value of each to monitor parasite resistance to specific drugs.

After a long history of 4-aminoquinoline use which has been accompanied by accumulating reports about increasing levels of AQ and CQ resistance [19,20], official drug policy for uncomplicated malaria in Papua New Guinea (PNG) was changed to the combination therapy of AQ or CQ plus SP in 2000. Although high levels of polymorphisms in CQ relevant genes pfcrt and $p f m d r 1$, and also to a lesser extent in key markers responsible for resistance to SP, have already been reported in PNG $[21,22]$, their association with in vivo treatment outcome has never been evaluated.

In this study, the genetic profile of parasites collected from pre-treatment samples of malaria patients attending two health facilities in PNG with known clinical and parasitological outcomes after treatment with $\mathrm{AQ}+\mathrm{SP}$ was analyzed. Twenty-four key markers in $p f m d r 1, p f c r t, p f d h f r$ and pfdhps were determined using a new DNA microarraybased technology. The association between parasite genetic output and treatment response was investigated to identify the most useful predictors of failure with the current first-line regimen in the country.

\section{Materials and methods In vivo assessment of drug efficacy}

Drug efficacy studies were conducted according to the standardized WHO protocol for low to moderate transmission areas [2] and are described in detail elsewhere [23]. Children between six months and seven years of age were enrolled if they were presenting at the health centre with clinically overt and microscopically confirmed $P$. falciparum malaria and no danger signs for severe or complicated malaria or signs of any other disease, malnutrition or anaemia. Standard AQ plus SP first line-treatment (10 mg AQ per kg on Day 0, 1 and 2, and 25 mg sulphadoxine per kg plus $1.25 \mathrm{mg}$ pyrimethamine per kg on Day 0) was administered under supervision over the first three days. Visits for the follow-up were scheduled on Day 1, 2, 3, 7, 14 , and 28 . On every visit, patients were clinically exam- 
ined and a Giemsa-stained blood slide was taken for the microscopic assessment of parasitaemia. A blood sample was taken on Day 0 (pre-treatment sample) and on Days 14 and 28 or any day of treatment failure for molecular genotyping purposes. At the end of the follow-up, the patients were classified according to their clinical and parasitological responses into early treatment failure (ETF), late clinical failure (LCF), late parasitological failure (LPF), or adequate clinical and parasitological response (ACPR) (WHO, 2003).

\section{Study sites and population}

The studies were conducted between October 2003 and April 2004 in the Karimui area (Simbu Province) and the South Wosera area (East Sepik Province), two rural places mesoendemic for malaria but differing with regard to transmission intensity and drug use patterns [20]. Main characteristics of the study populations and the two sites are depicted in table 1.

Scientific approval and ethical clearance for the study was obtained from the Medical Research and Advisory Committee (MRAC) of the Ministry of Health in PNG and consent was obtained from parents or legal guardians prior to recruitment of each patient.

\section{Laboratory analyses}

Fingerprick blood samples for molecular genotyping purposes were collected on Day 0 (pre-treatment sample) in EDTA microtainer tubes. DNA was extracted using QIAamp ${ }^{\oplus}$ DNA Blood Kit (Qiagen, Hombrechtikon, Switzerland) according to the manufacturer's instructions.

Assessment of single nucleotide polymorphisms (SNPs) for drug resistant malaria was done for $p f m d r 1$ codons N86Y, Y184F, S1034C, N1042D and D1246Y, pfcrt codons K76T, H97Q, T152A, S163R, A220S, Q271E, N326D/S, I356L/T and R371I, pfdhfr condons A16V, N51I, C59R, S108N/T and I164L, and pfdhps codons S436A, A437G, K540E, A581G, and A613T/S. The method is based on parallel PCR amplification of the target sequences followed by primer extension mediated minisequencing using fluorochrome-labelled ddNTPs. Subsequent base calling occurs on a microarray upon sequence specific hybridization [24].

Assessment of the multiplicity of infection (MOI) in pretreatment samples and the differentiation between true recrudescences and new infections in treatment failure samples was done by PCR-RFLP analysis of the merozoite surface protein $2(m s p 2)$ as previously described $[25,26]$.

\section{Statistics}

Statistical analyses were performed by the use of STATA software (version 8.2; Stata Corp., College Station, Texas). The strength of association was evaluated by calculating odds ratios (OR). $\chi^{2}$ tests and Fisher's exact test and where applicable stepwise logistical regression analyses were used to assess the significance of association between known risk factors and single or multiple mutations and treatment failure.

To estimate the allele frequencies of resistance markers in the study sample set, a non-linear statistical model that takes into account the effects of varying multiplicity of infection and assumes that resistant and sensitive parasite clones are transmitted independently was applied. The likelihood of a sample containing no resistant clones is ( 1 $-p)^{n}$, where $p$ is the frequency for the mutant allele and $n$ is the multiplicity of infection of the sample. Similarly, the likelihood for the sample to contain no wild-type allele is $p^{n}$ and for a mixture of both, a wild-type and a resistant

Table I: Baseline characteristics of study sites and patients at enrolment

\begin{tabular}{|c|c|c|}
\hline \multirow[b]{2}{*}{ Characteristics } & \multicolumn{2}{|c|}{ Study site } \\
\hline & Karimui area (Simbu Province) & South Wosera (East Sepik Province) \\
\hline Study sites & $\mathrm{n}=80$ & $n=94$ \\
\hline Endemicity* & mesoendemic & mesoendemic \\
\hline Transmission intensity§ & moderate & high \\
\hline \multicolumn{3}{|l|}{ Patients } \\
\hline Weight (mean $(95 \% \mathrm{Cl}), \mathrm{kg})$ & |3.8 (|2.9-14.6) & $14.4(13.8-15.1)$ \\
\hline Age (mean $(95 \% \mathrm{Cl})$, yrs) & $4.0(3.7-4.4)$ & $4.5(4.2-4.8)$ \\
\hline Sex: female/n (\%) & $43 / 97(44.3)$ & $59 / 112(52.7)$ \\
\hline Temperature (mean $\left.(95 \% \mathrm{Cl}),{ }^{\circ} \mathrm{C}\right)$ & $38.7(38.5-38.9)$ & $38.7(38.4-39.0)$ \\
\hline Haemoglobin (mean $(95 \% \mathrm{Cl}), \mathrm{g} / \mathrm{dl})$ & $9.0(8.6-9.5)$ & $9.0(8.7-9.3)$ \\
\hline Parasite density (geometric mean (range), per $\mu \mathrm{l}$ ) & $21937(1120-329400)$ & $40526(280-774400)$ \\
\hline Multiplicity of infection $(=\mathrm{MOI})($ mean $(95 \% \mathrm{Cl}))$ & $1.48(1.34-1.63)$ & $1.73(1.59-1.88)$ \\
\hline Spleen rate ${ }^{\#}(\%$ (95\% Cl)) & $43.3(33.3-53.7)$ & $50.9(41.3-60.5)$ \\
\hline
\end{tabular}

* Assessed by concomitant cross-sectional surveys in both study areas which showed $P$. falciparum prevalence rates of $1 \mathrm{I}-50 \%$ in children aged $2-9$ years (WHO, 2003); § Müller et al., 2003; \# proportion of children with enlarged spleen 
allele, is $1-p^{n}-(1-p)^{n}$. The likelihood over the whole data set for $p$ is computed as the product of this likelihood over all samples, using values of $n$ derived from $m s p 2$ genotyping results. Allele frequencies were added by maximising this likelihood using a simple one dimensional search routine. This gave very similar estimates to those made using a corresponding Bayesian algorithm [27]. Confidence intervals were calculated using bootstrap sampling.

\section{Results}

\section{In vivo drug efficacy}

A total of 80 patients in Karimui and 94 patients in the Wosera were enrolled into the study and treated with $\mathrm{AQ}+\mathrm{SP}$ (median age of 4 years). Day-28 treatment failure rates for $P$. falciparum after PCR-correction, classifying infections with new and recurrent strains as true recrudescences (i.e., treatment failures), were $29 \%$ in the Karimui and $19 \%$ in the Wosera area, respectively (Table 2 ).

\section{Prevalence and relationship of pfmdrl, pfcrt, pfdhfr and pfdhps mutations}

Mutation analyses were successfully accomplished in all 174 pre-treatment samples from both study sites. Polymorphisms were found in $p f m d r 1$ codons N86Y, Y184F, and N1042D, pfcrt codons K76T, A220S, N326D and I356L, pfdhfr codons C59R and S108N, and pfdhps codons A437G and K540E. None of the other SNPs $(11 / 24)$ was detected as mutated allele in any of the infections analysed.

Regarding CQ relevant molecular markers, infections with mutated $p f m d r 1 \mathrm{~N} 86 \mathrm{Y}$ and $p f c r t \mathrm{~K} 76 \mathrm{~T}, \mathrm{~N} 326 \mathrm{D}, \mathrm{I} 356 \mathrm{~L}$ and A220S alleles were with $86 \%, 91 \%, 89 \%, 89 \%$, and $70 \%$ very common, whereas $5 \%, 1 \%, 1 \%, 0 \%$, and $2 \%$ of these infections were mixed with a wild-type allele (Figure 1). The mutated alleles in $p f m d r 1 \mathrm{Y} 184 \mathrm{~F}$ and $p f m d r 1 \mathrm{~N} 1042 \mathrm{D}$

Table 2: Treatment outcomes for amodiaquine plus sulphadoxine-pyrimethamine against $P$. falciparum malaria in Papua New Guinea

\begin{tabular}{lcc}
\hline & \multicolumn{2}{c}{ Karimui area } \\
& $\mathrm{n}=80$ & $\begin{array}{c}\text { South Wosera area } \\
\mathrm{n}=94\end{array}$ \\
\hline Outcome* & \multicolumn{2}{c}{ Number (\%) } \\
\hline ACPR & $57(71.2)$ & $74(81.3)$ \\
ETF & $1(1.3)$ & $5(5.5)$ \\
LCF & $6(7.5)$ & $1(1.1)$ \\
LPF & $16(20.0)$ & $11(12.1)$ \\
\hline Total TF & $23(28.8)$ & $17(18.7)$ \\
\hline
\end{tabular}

* PCR-corrected values up to Day 28; ACPR, Adequate clinical and parasitological response; ETF, Early treatment failure; LCF, Late clinical failure; LPF, Late parasitological failure; TF, Treatment failure were only found in five (3\%) and two (1\%) samples, respectively, with the latter being detected as mixed allele only. Considering relationships of mutated alleles in $p f c r t$, the mutations N326D and I356L were always linked, the double mutation N326D+I356L never occurred without a mutated allele $\mathrm{K} 76 \mathrm{~T}$, and a mutation A220S never occurred without the triple mutation K76T+N326D+I356L. Considering pfmdr1, a mutation N1042D was always linked to a mutated Y184F allele, but these mutated alleles never occurred together with a N86Y mutation.

Regarding SP relevant molecular markers, mutations in pfdhfr S108N and C59R were also very common with 79\% and $77 \%$ of infections having a pure mutant, and $91 \%$ and $82 \%$ of infections having a mutant or mixed allele, respectively. Mutated alleles in $p f d h p s$ A437G were found in $13 \%$ of all infections whereas in $10 \%$ it was detected as a pure mutant. The pfdhps K540E mutation was only found in two samples and was only detected as pure mutant allele. Pfdhfr C59R was never detected without $p f d h f r$ S108N, and pfdhps mutations A437G and K540E were strongly linked to the double mutation $p f d h f r$ S108N+C59R, with only two of the samples having the pfdhps A437G mutation with concomitant wild-type alleles in $p f d h f r$.

\section{Association between pfmdrl, pfcrt, pfdhfr and pfdhps alleles and treatment outcome}

All patient isolates were coded according to presence or absence of mutant alleles and isolates showing both, wildtype and mutant allele, were treated as mutant. Likewise, infecting genotypes were coded according to the most highly mutated $p f m d r 1, p f c r t, p f d h f r$ and $p f d h p s$ alleles present in the sample.

Apart from $p f m d r 1$ N86Y (OR $=7.87,95 \%$ CI: $1.03-60.36$, $p<0.01)$ and pfdhps A437G (OR $=3.44,95 \%$ CI: $1.40-$ $8.47, p<0.01)$, there was no independent marker found to be significantly associated with treatment failure (Table $3)$. When known confounding factors, such initial parasite density, age, and multiplicity of infection (MOI), were adjusted for in a stepwise logistical regression model, the significant associations for the two above-mentioned markers were retained.

Twenty three different genotypes could be discriminated with regard to mutated gene loci in all four genes analysed (Table 4). Among those, seven were observed in treatment failure cases, whereas the remaining 16 were exclusively found in patients with an adequate treatment response. Associations between these genotypes and treatment failure can be summarized as follows. Odds ratios for treatment failure were only increased for genotypes having the $\mathrm{N} 86 \mathrm{Y}$ mutation in pfmdr1 combined with the double 


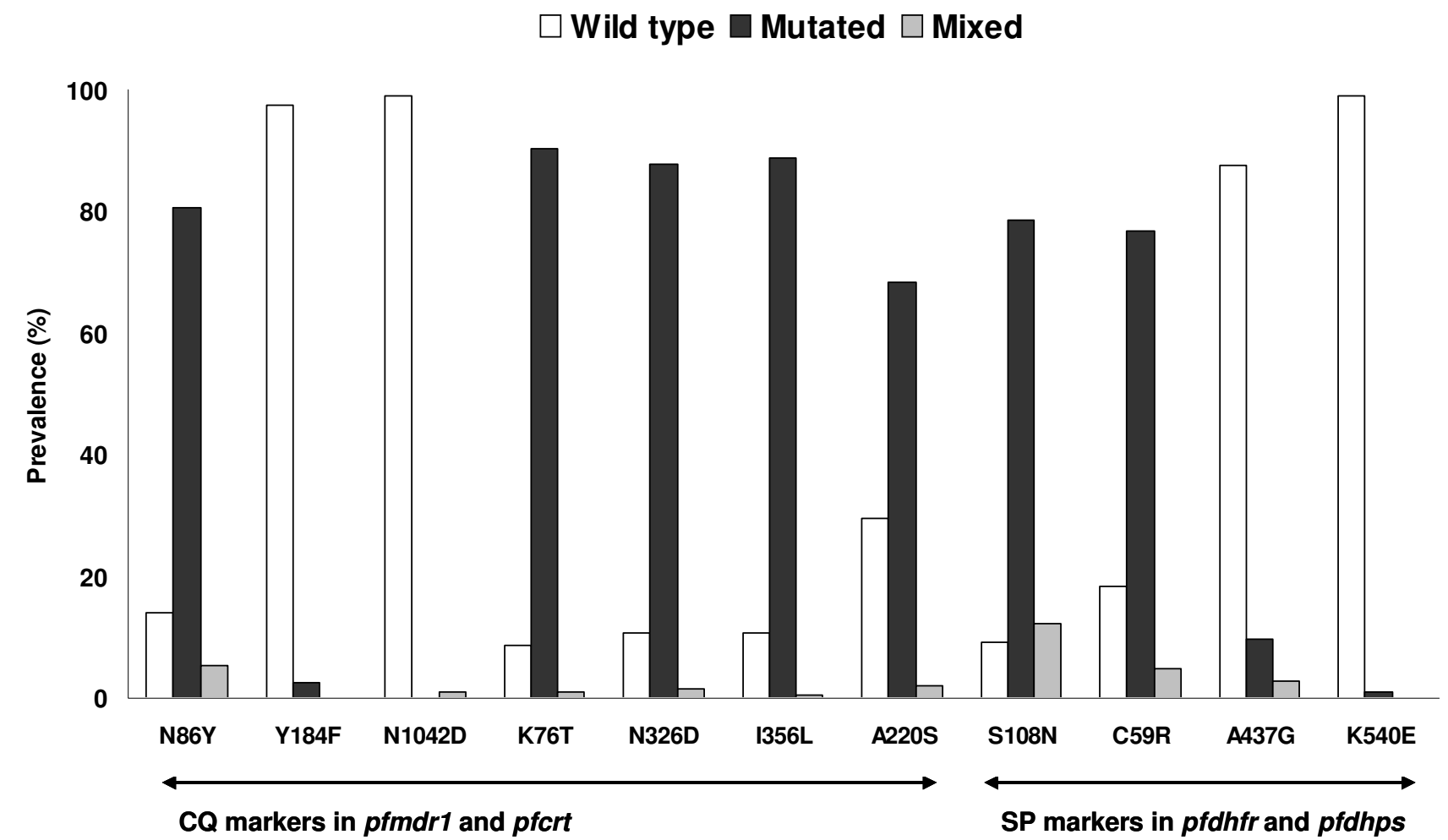

Figure I

Prevalence of mutations in pfmdrl, pfcrt, pfdhfr and pfdhps in patient samples from Papua New Guinea. CQ, chloroquine; SP, sulphadoxine-pyrimethamine; $p \mathrm{fmdrl}$, Plasmodium falciparum multidrug resistance gene I; $p f c r t$, Plasmodium falciparum chloroquine resistance transporter; $p f d h f r$, Plasmodium falciparum dihydrofolate reductase; pfdhps, Plasmodium falciparum dihydropteroate synthase; no mutation was detected in any of the other SNP sites analysed (I3/24 sites).

Table 3: Association between mutated single markers in pfcrt, pfmdrl, pfdhfr and pfdhps and treatment failure with amodiaquine plus sulphadoxine-pyrimethamine

\begin{tabular}{|c|c|c|c|c|}
\hline Gene & Polymorphism & OR & 95\% Confidence Interval & $p($ LRT) \\
\hline pfcrt & $\mathrm{K} 76 \mathrm{~T}$ & 2.09 & $0.45-9.70$ & 0.31 \\
\hline pfort & I326L & 2.64 & $0.58-12.03$ & 0.16 \\
\hline pfort & N356D & 2.64 & $0.58-12.03$ & 0.16 \\
\hline pfor & A220S & 1.23 & $0.55-2.75$ & 0.62 \\
\hline pfmdrl & N86Y & 7.87 & $1.03-60.36$ & $<0.01$ \\
\hline pfmdrI & YI84F & $\S$ & & \\
\hline pfmdrl & NI042D & $\S$ & & \\
\hline pfdhfr & SI08N & 0.74 & $0.22-2.51$ & 0.64 \\
\hline pfdhfr & C59R & 2.34 & $0.77-7.14$ & 0.11 \\
\hline pfdhps & A437G & 3.44 & $1.40-8.47$ & $<0.01$ \\
\hline pfdhps & $\mathrm{K} 540 \mathrm{E}$ & $\S$ & & \\
\hline
\end{tabular}

OR, odds ratio; LRT, likelihood ratio test; pfcrt, Plasmodium falciparum chloroquine resistance transporter; pfmdrl, Plasmodium falciparum multidrug resistance gene I; pfdhfr, Plasmodium falciparum dihydrofolate reductase; pfdhps, Plasmodium falciparum dihydropteroate synthase; $\S$ mutated alleles were not detected in samples from treatment failure cases 
Table 4: Association between infecting pfcrt, pfmdrl, pfdhfr and $p f d h p s$ genotypes and treatment failure with amodiaquine plus sulphadoxine-pyrimethamine

\begin{tabular}{|c|c|c|c|c|c|c|c|c|c|c|c|c|}
\hline \multirow[b]{3}{*}{ K76T } & \multirow{2}{*}{\multicolumn{3}{|c|}{$\begin{array}{l}\text { CQ-relevant markers } \\
\text { pfcrt }\end{array}$}} & \multirow{3}{*}{$\frac{\text { pfmdr I* }}{\text { N86Y }}$} & \multicolumn{4}{|c|}{ SP-relevant markers } & \multirow[b]{3}{*}{$\mathrm{P}(\%)$} & \multirow[b]{3}{*}{ OR } & \multirow[b]{3}{*}{$95 \% \mathrm{Cl}$} & \multirow[b]{3}{*}{$p\left(\chi^{2}\right)$} \\
\hline & & & & & & & $p f c$ & & & & & \\
\hline & N326D & I356L & A220S & & SI08N & C59R & A437G & K540E & & & & \\
\hline & & & & & & & & & 1.2 & $\S$ & & \\
\hline & & & & & $\mathbf{x}$ & & & & 0.6 & $\S$ & & \\
\hline & & & & & $\mathbf{x}$ & $\mathbf{x}$ & & & 1.7 & $\S$ & & \\
\hline $\mathbf{x}$ & & & & & & & & & 0.6 & $\S$ & & \\
\hline $\mathbf{x}$ & & & & & $\mathbf{x}$ & $\mathbf{x}$ & & & 0.6 & $\S$ & & \\
\hline $\mathbf{x}$ & $\mathbf{x}$ & $\mathbf{x}$ & & & $\mathbf{x}$ & $\mathbf{x}$ & & & 0.6 & $\S$ & & \\
\hline $\mathbf{x}$ & $\mathbf{x}$ & $\mathbf{x}$ & $\mathbf{x}$ & & & & & & 0.6 & $\S$ & & \\
\hline $\mathbf{x}$ & $\mathbf{x}$ & $\mathbf{x}$ & $\mathbf{x}$ & & $\mathbf{x}$ & & & & 0.6 & $\S$ & & \\
\hline \multirow[t]{4}{*}{$\mathbf{x}$} & $x$ & $\mathbf{x}$ & $\mathbf{x}$ & & $x$ & $\mathbf{x}$ & & & 7.0 & 0.28 & $0.03-2.24$ & 0.16 \\
\hline & & & & $\mathbf{x}$ & & & & & 0.6 & $\S$ & & \\
\hline & & & & $\mathbf{x}$ & $\mathbf{x}$ & & & & 1.2 & $\S$ & & \\
\hline & & & & $\mathbf{x}$ & $\mathbf{x}$ & $\mathbf{x}$ & & & 3.5 & 1.67 & $0.29-9.48$ & 0.57 \\
\hline $\mathbf{x}$ & & & & $\mathbf{x}$ & $\mathbf{x}$ & $\mathbf{x}$ & & & 0.6 & $\S$ & & \\
\hline$x$ & $x$ & $x$ & & $x$ & & & & & 0.6 & $\S$ & & \\
\hline $\mathbf{x}$ & $x$ & $x$ & & $\mathbf{x}$ & $\mathbf{x}$ & & & & 1.2 & $\S$ & & \\
\hline$x$ & $x$ & $x$ & & $x$ & $x$ & $x$ & & & 11.7 & 1.10 & $0.38-3.25$ & 0.86 \\
\hline $\mathbf{x}$ & $x$ & $x$ & & $x$ & $x$ & $x$ & $\mathbf{x}$ & & 3.5 & 3.46 & $0.67-17.86$ & 0.15 \\
\hline$x$ & $x$ & $x$ & $x$ & $x$ & & & & & 3.5 & 7.17 & $|.26-40.7|$ & 0.02 \\
\hline$x$ & $x$ & $\mathbf{x}$ & $x$ & $x$ & & & & $x$ & 1.2 & $\S$ & & \\
\hline$x$ & $x$ & $x$ & $x$ & $x$ & $x$ & & & & 6.4 & $\S$ & & \\
\hline$x$ & $x$ & $x$ & $x$ & $x$ & $\mathbf{x}$ & $\mathbf{x}$ & & & 42.7 & 1.00 & $0.48-2.03$ & 0.98 \\
\hline$x$ & $x$ & $x$ & $x$ & $x$ & $x$ & $\mathbf{x}$ & $x$ & & 9.3 & 3.84 & $1.34-11.03$ & $<0.01$ \\
\hline$x$ & $x$ & $x$ & $x$ & $x$ & $x$ & $x$ & & $x$ & 0.6 & $\S$ & & \\
\hline
\end{tabular}

* due to very low mutation rates, genotypes with mutated gene loci YI84F and NI042D in pfmdrl were grouped together with the wild-type pfmdr I genotypes; AQ, amodiaquine; SP, sulphadoxine-pyrimethamine; pfcrt, Plasmodium falciparum chloroquine resistance transporter; pfmdrl, Plasmodium falciparum multidrug resistance gene I; pfdhfr, Plasmodium falciparum dihydrofolate reductase; pfdhps, Plasmodium falciparum dihydropteroate synthase; P, prevalence; OR, odds ratio; $X$, mutated allele; $\S$ the genotype was not detected in samples from treatment failure cases

mutation S108N+C59R in pfdhfr, regardless of the concomitant genotype in $p f c r t$. However, the risk for failure reached only statistical significance for genotypes having the pfmdr1 N86Y mutation in conjunction with the quadruple mutation $\mathrm{K} 76 \mathrm{~T}+\mathrm{A} 220 \mathrm{~S}+\mathrm{N} 326 \mathrm{D}+\mathrm{I} 356 \mathrm{~L}$ in pfcrt and the A437G allele in pfdhps (OR $=3.84,95 \% \mathrm{CI}: 1.34-$ $11.03, p<0.01)$. Furthermore, a significant association was also observed with the genotype harbouring the $p f c r t$ quadruple mutant plus $p f m d r 1 \mathrm{~N} 86 \mathrm{Y}$ without any concurrent mutations in $p f d h f r$ or $p f d h p s(\mathrm{OR}=7.17,95 \% \mathrm{CI}$ : $1.26-40.71, p=0.02$ ).

Mutant allele frequencies and treatment outcome by site To investigate whether the difference in treatment outcome at the two study sites was reflected in the drug resistance profile of the corresponding parasites, mutant allele frequencies for each gene locus were calculated. Maximum likelihood estimates of mutant allele frequencies found in the two study populations are presented in Figure 2. Regarding the allele frequencies for the CQ relevant molecular markers, there was no significant difference in pfcrt K76T, N326D, and I356L. The only statistically sig- nificant differences in allele frequencies between the Karimui and the Wosera area were found for $p f c r t$ A220S ( 0.56 versus $0.81, p<0.0001)$, pfmdr 1 N86Y ( 0.99 versus $0.70, p<0.0001)$ and $p f m d r 1 \mathrm{Y} 184 \mathrm{~F}(0.00$ versus $0.04, p=$ $0.001)$. A similar picture was observed for the SP relevant molecular markers. Whereas the difference in any of the mutated loci in $p f d h f r$ was not significant, the genetic profile for $p f d h p s$ mutation A437G was significantly different in the two parasite populations with an allele frequency of 0.25 in the Karimui area versus 0.02 in the Wosera area ( $p$ $<0.0001)$.

\section{Discussion}

The genetic drug resistance profile was established in pretreatment samples from malaria patients in Karimui and the Wosera by the use of a new DNA microarray-based technology [24] and its relationship with in vivo drug response to the combinations of $\mathrm{AQ}+\mathrm{SP}$ was analysed. The principal objectives were to establish the baseline prevalence of polymorphisms in genes related to AQ/CQ and SP resistance, to assess their relationship with treatment outcome, in order to identify and propose useful 


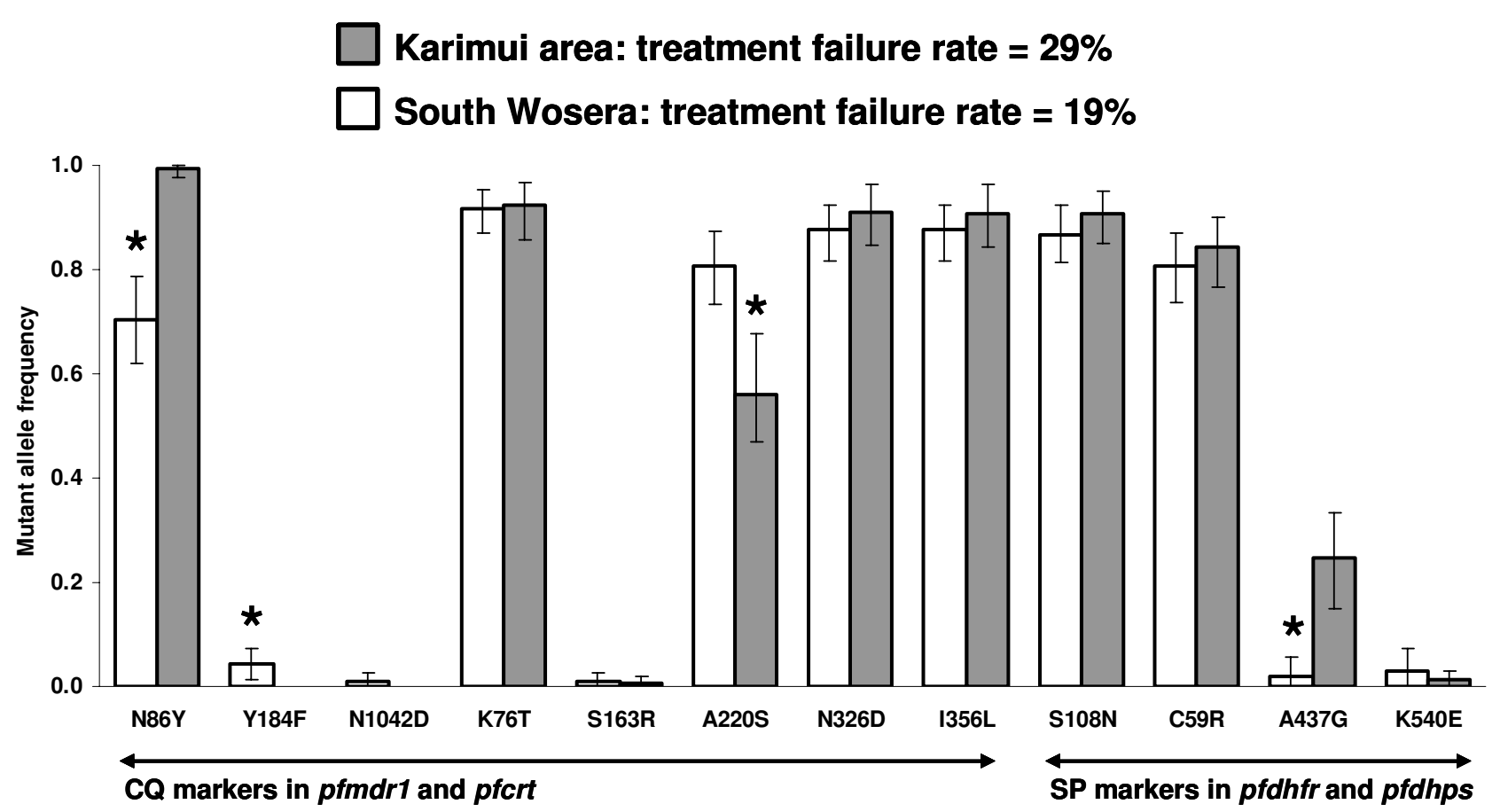

Figure 2

Maximum likelihood estimates of mutant allele frequencies at the two study sites. Error bars denote $95 \%$ confidence intervals; * denotes statistical significance at the $95 \%$ level; CQ, chloroquine; SP, sulphadoxine-pyrimethamine; $p f m d r l$, Plasmodium falciparum multidrug resistance gene I; pfcrt, Plasmodium falciparum chloroquine resistance transporter; pfdhfr, Plasmodium falciparum dihydrofolate reductase; pfdhps, Plasmodium falciparum dihydropteroate synthase.

markers for molecular monitoring of drug resistant $P$. falciparum in the country.

The analysis of the genetic profile of the parasite population revealed high levels of mutant alleles in CQ resistance (CQR) related $p f c r t$ and $p f m d r 1$ genes. The long history of 4-aminoquinoline use as monotherapy in PNG has led to a highly CQ resistant genetic background in the parasites as reported previously $[21,28]$. In addition, the results demonstrated prevalence rates of $91 \%$ and $82 \%$ for mutant alleles in the pyrimethamine related gene loci $p f d$ $h f r$ S108N and C59R. Mita et al. [29] recently analysed $P$. falciparum isolates from patients attending town clinics in Wewak (East Sepik Province) and observed similarly high prevalence rates of $p f d h f r$ double S108N+C59R mutations ( $83 \%$ in 2002 and $86 \%$ in 2003). These high levels of mutation rates in $p f d h f r$ appearing only a short time after the implementation of SP as one component of the official first-line policy were not surprising and may be due to i) the increasing recourse to SP as second-line therapy with quinine in the late 1990s (Nsanzabana et al., unpublished), ii) the former drug pressure exerted by the use of pyrimethamine (in combination with CQ) in mass drug administration campaigns in the 1960s and 1970s [30], and iii) the widespread use of trimethoprim-sulphamethoxazole for the treatment of bacterial infections $[31,32]$. Recent microsatellite analysis in $d h f r$-flanking regions by Mita et al. [29] revealed that the most prevalent $d h f r$ haplotype (i.e., S108N+C59R double mutation) was associated with reduced microsatellite variability around the gene, an observation which argues for the selection of preexisting SP resistant parasites, rather than the frequent emergence of de novo mutations in this gene [33]. These data further corroborate the hypothesis, that former drug pressure has lead to the emergence of pyrimethamine resistant parasites before the official introduction of SP in PNG.

Until 2003, polymorphic pfdhps loci associated with reduced sensitivity to sulpha drugs have only been found in a single $P$. falciparum isolate originating from PNG $[21,22]$. In the present study, prevalence rates of $13 \%$ for A437G and 1\% for K540E were observed. Likewise, Mita and colleagues detected mutations in these loci in $8 \%$ of patient isolates collected in Wewak in the year 2003. In the view that $p f d h f r$ mutations usually predominate over 
those in $p f d h p[12,15]$, the detection of genotypes having a single $d h p s$ A437G mutation in combination with $p f d h f r$ wild type alleles in two of the samples was rather unusual. However, this genotype may well have been selected by sulpha drugs used to treat infectious diseases other than malaria.

In order to propose a suitable marker set for the molecular monitoring of $P$. falciparum against the current combination therapy, the association of single mutations as well as infecting genotypes with in vivo treatment response was investigated. Regarding CQ relevant markers, the only single marker associated with a significantly increased risk of treatment failure was $p f m d r 1 \mathrm{~N} 86 \mathrm{Y}$. Taking into account additional SNPs in pfcrt, neither of the mutated alleles increased the predictive value for $p f m d r 1 \mathrm{~N} 86 \mathrm{Y}$, the most likely reason being that these mutations nearly reached fixed levels in the parasite population. Similarly, pyrimethamine relevant markers in $p f d h f r$ did not show a significant association with treatment failure. Risk of failure was only increased with infections harbouring the A437G mutation in pfdhps. These observations are in agreement with previous studies showing that the prevalence of single molecular markers (e.g. pfcrt K76T or pfdhfr S108N) was almost always higher than the level of clinical or parasitological resistance to the respective drugs, especially in regions with high transmission intensity and long lasting drug pressure $[4,34]$ and therefore, renders these markers unsuitable for molecular monitoring. Furthermore, the validity of molecular markers is dependent on former drug use and may also vary according to the malaria epidemiology in a given area $[10,17,18]$. The evaluation and assessment of a combination of markers, instead of single markers indicating the presence of a highly resistant genotype, have been suggested for the molecular monitoring of antimalarial resistance $[12,14$ $16,35,36]$. In the present study, which took into account the combined $p f c r t / p f m d r 1 / p f d h f r / p f d h p s$ genotype, the risk of treatment failure was clearly associated with the total number of mutations in the analysed genes. The risk was significantly increased for patients harbouring parasites with the most highly mutated genotype (i.e., 8/24 SNPs mutated). However, unusual findings included the increased risk of treatment failure with genotypes having the N86Y mutation in pfmdr1 and the quadruple mutation in $p f c r t$ combined with a fully wild type $p f d h f r+p f d h p s$ allele. These results highlight again the fact that among many parasite and host factors, the molecular resistance background of $P$. falciparum is only one of several determinants for in vivo treatment outcome. Whereas acquired immunity can account for the clearance of drug resistant genotypes, diminished drug metabolism may well explain treatment failure in spite of an infection with a susceptible genotype [37].
Regarding former drug history in PNG, the relevance of key $p f d h p s$ mutations in predicting treatment failure was expected. AQ and CQ as inefficacious partner drugs of SP in the new standard regimen were not able to curb both, the progression of pyrimethamine resistance as well as the emergence of sulphadoxine resistance. It is most likely that in this sample, clinical efficacy of the sulpha component was mainly assessed. However, according to the present results, also $p f m d r 1$ N86Y plays an important role in predicting a negative treatment response. CQ and AQ are chemically related drugs and cross-resistance has been described in several clinical and in vitro reports. Though little is known about the genetic mechanisms conferring AQ resistance [38], an important role has been ascribed to the key CQR markers pfcrt K76T and pfmdr1 N86Y [39,40]. It has been shown recently that in combination with $p f c r t$ $\mathrm{K} 76 \mathrm{~T}$, the $p f m d r 1 \mathrm{~N} 86 \mathrm{Y}$ polymorphism was predictive for treatment failure with AQ in Nigeria [41] and that AQ resistance was associated with the selection of these polymorphisms in Kenya [42]. Considering the long use of AQ as monotherapy against uncomplicated falciparum malaria in PNG and the observation that $p f m d r 1 \mathrm{~N} 86 \mathrm{Y}$ is a strong predictor for treatment failure with $\mathrm{AQ}+\mathrm{SP}$, the present data support the hypothesis that $p f m d r 1 \mathrm{~N} 86 \mathrm{Y}$ is probably involved in AQ resistance. Several studies have shown that both, SNPs and gene amplification of pfmdr1, can mediate resistance to 4 -aminoquinlines and also other drug classes, such as amino alcohols and artemisinin derivates [43] However, results from different studies investigating the relationship of these genetic alterations in $p f m d r 1$ and in vivo response were often inconsistent $[6,44]$. Direct (active drug translocation) and indirect (modification of biophysical cell parameters) modes of action have been proposed for P-glycoprotein homolog 1, the gene product of $p f m d r 1$. But how genetic alterations in $p f m d r 1$ and epistatic interactions with other genes finally lead to a multidrug resistant phenotype remains to be resolved [45].

Finally, the fact that the difference in clinical outcome between the two sites was reflected in the genetic profile of the corresponding parasite populations, especially for the frequencies of $p f m d r 1 \mathrm{~N} 86 \mathrm{Y}$ and $p f d h p s \mathrm{~A} 437 \mathrm{G}$, further confirmed the role of these two markers as important predictors for a negative treatment response with $A Q+S P$ and suggests them to be the most useful resistance surveillance markers with the current standard treatment in PNG.

\section{Conclusion}

This study shows that a careful baseline assessment of molecular markers, including the investigation of their relationship with treatment response, is essential for the identification of appropriate marker sets. For the parallel analysis of SNPs in multiple genes in a large sample size, DNA microarray technology has proven to be a valuable 
and cost-effective tool. However, the use of additional markers could become necessary for the longitudinal resistance monitoring in the future, in particular when current drug policy starts to show reduced effectiveness. These may include SNPs in known or as yet uncharacterized genes involved in resistance to the commonly used antimalarials, or markers against newly implemented drug classes, such as the artemisinins.

\section{Authors' contributions}

JM participated in the coordination of the field and laboratory studies, performed data acquisition and molecular and statistical analyses and drafted the manuscript. IM, $\mathrm{AS}$, OO and JCR participated in the coordination of the field studies. BG, HPB, and TAS participated in the design of the study, the statistical analysis and the drafting of the manuscript. All authors read and approved the final manuscript.

\section{Acknowledgements}

We thank all the study participants and their parents or legal guardians who made themselves available for these studies. We thank all the field and laboratory staff at the Papua New Guinea Institute of Medical Research branches in Goroka and Maprik, notably Rex Ivivi, Marc Gomobi, Peter Maku, Merolyn Uranoli, Donald Abari and Moses Lagog, for their assistance with patient recruitment and microscopical analysis.

Financial Support: This study was supported by the Swiss National Science Foundation (Grant no: 3100-AO-103968).

\section{References}

I. White NJ, Olliaro PL: Strategies for the prevention of antimalarial drug resistance: rationale for combination chemotherapy for malaria. Parasitol Today 1996, I 2:399-40 I.

2. World Health Organisation (WHO): Assessment and Monitoring of Antimalarial Drug Efficacy for the Treatment of Uncomplicated Falciparum Malaria. Geneva, Switzerland, World Health Organization (WHO) 2003, WHO/HTM/RBM/2003.50:

3. Babiker HA, Pringle SJ, Abdel-Muhsin A, Mackinnon M, Hunt P, Walliker D: High-level chloroquine resistance in Sudanese isolates of Plasmodium falciparum is associated with mutations in the chloroquine resistance transporter gene pfort and the multidrug resistance Gene pfmdrl. J Infect Dis 200I, 183:1535-1538.

4. Djimde A, Doumbo OK, Cortese JF, Kayentao K, Doumbo S, Diourte Y, Dicko A, Su XZ, Nomura T, Fidock DA, Wellems TE, Plowe CV, Coulibaly D: A molecular marker for chloroquine-resistant falciparum malaria. N Engl J Med 200I, 344:257-263.

5. Basco LK, Ringwald P: Molecular epidemiology of malaria in Yaounde, Cameroon. III. Analysis of chloroquine resistance and point mutations in the multidrug resistance I (pfmdr I) gene of Plasmodium falciparum. Am J Trop Med Hyg 1998, 59:577-581.

6. Pillai DR, Labbe AC, Vanisaveth $V$, Hongvangthong B, Pomphida S, Inkathone S, Zhong K, Kain KC: Plasmodium falciparum malaria in Laos: chloroquine treatment outcome and predictive value of molecular markers. J Infect Dis 200I, I83:789-795.

7. Basco LK, Tahar R, Ringwald $P$ : Molecular basis of in vivo resistance to sulfadoxine-pyrimethamine in African adult patients infected with Plasmodium falciparum malaria parasites. Antimicrob Agents Chemother 1998, 42:1811-18|4.

8. Basco LK, Tahar R, Keundjian A, Ringwald P: Sequence variations in the genes encoding dihydropteroate synthase and dihydrofolate reductase and clinical response to sulfadoxinepyrimethamine in patients with acute uncomplicated falciparum malaria. J Infect Dis 2000, 182:624-628.
9. Wang P, Lee CS, Bayoumi R, Djimde A, Doumbo O, Swedberg G, Dao LD, Mshinda H, Tanner M, Watkins WM, Sims PF, Hyde JE: Resistance to antifolates in Plasmodium falciparum monitored by sequence analysis of dihydropteroate synthetase and dihydrofolate reductase alleles in a large number of field samples of diverse origins. Mol Biochem Parasitol 1997, 89:161-I77.

10. Alifrangis M, Enosse S, Khalil IF, Tarimo DS, Lemnge MM, Thompson R, Bygbjerg IC, Ronn AM: Prediction of Plasmodium falciparum resistance to sulfadoxine/pyrimethamine in vivo by mutations in the dihydrofolate reductase and dihydropteroate synthetase genes: a comparative study between sites of differing endemicity. Am J Trop Med Hyg 2003, 69:60I-606.

II. Aubouy A, Jafari S, Huart V, Migot-Nabias F, Mayombo J, Durand R, Bakary M, Le Bras J, Deloron P: DHFR and DHPS genotypes of Plasmodium falciparum isolates from Gabon correlate with in vitro activity of pyrimethamine and cycloguanil, but not with sulfadoxine-pyrimethamine treatment efficacy. J Antimicrob Chemother 2003, 52:43-49.

12. Nzila AM, Mberu EK, Sulo J, Dayo H, Winstanley PA, Sibley CH, Watkins WM: Towards an understanding of the mechanism of pyrimethamine-sulfadoxine resistance in Plasmodium falciparum: genotyping of dihydrofolate reductase and dihydropteroate synthase of Kenyan parasites. Antimicrob Agents Chemother 2000, 44:991-996.

13. Kublin JG, Witzig RS, Shankar AH, Zurita JQ, Gilman RH, Guarda JA, Cortese JF, Plowe CV: Molecular assays for surveillance of antifolate-resistant malaria. Lancet 1998, 35 I:1629-1630.

14. Kublin JG, Dzinjalamala FK, Kamwendo DD, Malkin EM, Cortese JF, Martino LM, Mukadam RA, Rogerson S], Lescano AG, Molyneux ME, Winstanley PA, Chimpeni P, Taylor TE, Plowe CV: Molecular markers for failure of sulfadoxine-pyrimethamine and chlorproguanil-dapsone treatment of Plasmodium falciparum malaria. J Infect Dis 2002, 185:380-388.

15. Kyabayinze D, Cattamanchi A, Kamya MR, Rosenthal PJ, Dorsey G: Validation of a simplified method for using molecular markers to predict sulfadoxine-pyrimethamine treatment failure in African children with falciparum malaria. Am J Trop Med Hyg 2003, 69:247-252.

16. Talisuna AO, Nalunkuma-Kazibwe A, Langi P, Mutabingwa TK, Watkins WW, Van Marck E, Egwang TG, D'Alessandro U: Two mutations in dihydrofolate reductase combined with one in the dihydropteroate synthase gene predict sulphadoxinepyrimethamine parasitological failure in Ugandan children with uncomplicated falciparum malaria. Infect Genet Evol 2004, 4:32I-327.

17. Omar SA, Adagu IS, Warhurst DC: Can pretreatment screening for dhps and dhfr point mutations in Plasmodium falciparum infections be used to predict sulfadoxine-pyrimethamine treatment failure? Trans $R$ Soc Trop Med Hyg 200I, 95:315-3I9.

18. Staedke SG, Sendagire H, Lamola S, Kamya MR, Dorsey G, Rosenthal PJ: Relationship between age, molecular markers, and response to sulphadoxine-pyrimethamine treatment in Kampala, Uganda. Trop Med Int Health 2004, 9:624-629.

19. Genton B, Baea K, Lorry K, Ginny M, Wines B, Alpers MP: Parasitological and clinical efficacy of standard treatment regimens against Plasmodium falciparum, $P$. vivax and $P$. malariae in Papua New Guinea. P N G Med J 2005, 48: 14I- 150.

20. Muller I, Bockarie M, Alpers M, Smith T: The epidemiology of malaria in Papua New Guinea. Trends Parasitol 2003, 19:253-259.

21. Casey G], Ginny M, Uranoli M, Mueller I, Reeder JC, Genton B, Cowman AF: Molecular analysis of Plasmodium falciparum from drug treatment failure patients in Papua New Guinea. Am J Trop Med Hyg 2004, 70:25I-255.

22. Reeder JC, Rieckmann KH, Genton B, Lorry K, Wines B, Cowman AF: Point mutations in the dihydrofolate reductase and dihydropteroate synthetase genes and in vitro susceptibility to pyrimethamine and cycloguanil of Plasmodium falciparum isolates from Papua New Guinea. Am J Trop Med Hyg 1996, 55:209-213

23. Marfurt J, Mueller I, Sie A, Maku P, Goroti M, Reeder JC, Beck HP, Genton B: Low Efficacy of Amodiaquine or Chloroquine Plus Sulfadoxine-Pyrimethamine against Plasmodium falciparum and P. vivax Malaria in Papua New Guinea. Am J Trop Med Hyg 2007, 77:947-954. 
24. Crameri A, Marfurt J, Mugittu K, Maire N, Regos A, Coppee JY, Sismeiro O, Burki R, Huber E, Laubscher D, Puijalon O, Genton B Felger I, Beck HP: Rapid microarray-based method for monitoring of all currently known single-nucleotide polymorphisms associated with parasite resistance to antimalaria drugs. J Clin Microbiol 2007, 45:3685-369I.

25. Felger I, Beck HP: Genotyping of Plasmodium falciparum. PCR RFLP analysis. Methods Mol Med 2002, 72:I I7-I29.

26. Slater M, Kiggundu M, Dokomajilar C, Kamya MR, Bakyaita N, Talisuna $A$, Rosenthal PJ, Dorsey G: Distinguishing recrudescences from new infections in antimalarial clinical trials: major impact of interpretation of genotyping results on estimates of drug efficacy. Am J Trop Med Hyg 2005, 73:256-262.

27. Schneider AG, Premji Z, Felger I, Smith T, Abdulla S, Beck HP Mshinda $\mathrm{H}$ : A point mutation in codon 76 of pfort of $P$. falciparum is positively selected for by Chloroquine treatment in Tanzania. Infect Genet Evol 2002, I:183-189.

28. Nagesha HS, Casey GJ, Rieckmann KH, Fryauff DJ, Laksana BS, Reeder JC, Maguire JD, Baird JK: New haplotypes of the Plasmodium falciparum chloroquine resistance transporter (pfcrt) gene among chloroquine-resistant parasite isolates. Am J Trop Med Hyg 2003, 68:398-402

29. Mita T, Kaneko A, Hwaihwanje I, Tsukahara T, Takahashi N, Osawa $\mathrm{H}$, Tanabe K, Kobayakawa T, Bjorkman A: Rapid selection of dhfr mutant allele in Plasmodium falciparum isolates after the introduction of sulfadoxine/pyrimethamine in combination with 4-aminoquinolines in Papua New Guinea. Infect Genet Evol 2006, 6(6):447-452

30. Spencer $M$ : The history of malaria control in the southwest Pacific region, with particular reference to Papua New Guinea and the Solomon Islands. P N G Med J 1992, 35:33-66.

31. lyer JK, Milhous WK, Cortese JF, Kublin JG, Plowe CV: Plasmodium falciparum cross-resistance between trimethoprim and pyrimethamine. Lancet 200I, 358:1066-1067.

32. Khalil I, Ronn AM, Alifrangis M, Gabar HA, Satti GM, Bygbjerg IC: Dihydrofolate reductase and dihydropteroate synthase genotypes associated with in vitro resistance of Plasmodium falciparum to pyrimethamine, trimethoprim, sulfadoxine, and sulfamethoxazole. Am J Trop Med Hyg 2003, 68:586-589.

33. Pearce R, Malisa A, Kachur SP, Barnes K, Sharp B, Roper C: Reduced variation around drug-resistant dhfr alleles in African Plasmodium falciparum. Mol Biol Evol 2005, 22: |834- |844.

34. Rallon NI, Osorio LE, Giraldo LE: Lack of an association between the ASN-I08 mutation in the dihydrofolate reductase gene and in vivo resistance to sulfadoxine/pyrimethamine in Plasmodium falciparum. Am J Trop Med Hyg I999, 6 I :245-248.

35. Jelinek T, Aida AO, Peyerl-Hoffmann G, Jordan S, Mayor A, Heuschkel C, el Valy AO, von Sonnenburg F, Christophel EM: Diagnostic value of molecular markers in chloroquine-resistant falciparum malaria in Southern Mauritania. Am J Trop Med Hyg 2002, 67:449-453.

36. Khalil IF, Alifrangis M, Tarimo DS, Staalso T, Satti GM, Theander TG Ronn AM, Bygbjerg IC: The roles of the pfcrt 76T and pfmdr $86 Y$ mutations, immunity and the initial level of parasitaemia, in predicting the outcome of chloroquine treatment in two areas with different transmission intensities. Ann Trop Med Parasitol 2005, 99:44 I-448.

37. White NJ: The assessment of antimalarial drug efficacy. Trends Parasitol 2002, 18:458-464.

38. Meshnick SR, Alker AP: Amodiaquine and combination chemotherapy for malaria. Am J Trop Med Hyg 2005, 73:82 I-823.

39. Dokomajilar C, Lankoande ZM, Dorsey G, Zongo I, Ouedraogo JB, Rosenthal PJ: Roles of specific Plasmodium falciparum mutations in resistance to amodiaquine and sulfadoxinepyrimethamine in Burkina Faso. Am J Trop Med Hyg 2006, 75:162-165.

40. Ochong EO, van B IV, Keus K, Nzila A: Short report: association between chloroquine and amodiaquine resistance and allelic variation in the Plasmodium falciparum multiple drug resistance I gene and the chloroquine resistance transporter gene in isolates from the upper Nile in southern Sudan. Am J Trop Med Hyg 2003, 69:184-187.

41. Happi CT, Gbotosho GO, Folarin OA, Bolaji OM, Sowunmi A, Kyle DE, Milhous W, Wirth DF, Oduola AM: Association between mutations in Plasmodium falciparum chloroquine resistance transporter and P. falciparum multidrug resistance I genes and in vivo amodiaquine resistance in $\mathbf{P}$. falciparum malariainfected children in Nigeria. Am J Trop Med Hyg 2006, 75: $|55-16|$

42. Holmgren G, Gil JP, Ferreira PM, Veiga MI, Obonyo CO, Bjorkman A Amodiaquine resistant Plasmodium falciparum malaria in vivo is associated with selection of pfcrt $76 \mathrm{~T}$ and pfmdr I $86 \mathrm{Y}$. Infect Genet Evol 2006, 6:309-3 I4.

43. Reed MB, Saliba KJ, Caruana SR, Kirk K, Cowman AF: Pgh I modulates sensitivity and resistance to multiple antimalarials in Plasmodium falciparum. Nature 2000, 403:906-909.

44. Tinto H, Ouedraogo JB, Erhart A, Van Overmeir C, Dujardin JC, Van Marck E, Guiguemde TR, D'Alessandro U: Relationship between the Pfcrt T76 and the Pfmdr-I Y86 mutations in Plasmodium falciparum and in vitro/in vivo chloroquine resistance in Burkina Faso, West Africa. Infect Genet Evol 2003, 3:287-292.

45. Duraisingh MT, Refour P: Multiple drug resistance genes in malaria -- from epistasis to epidemiology. Mol Microbiol 2005, 57:874-877.
Publish with Biomed Central and every scientist can read your work free of charge

"BioMed Central will be the most significant development for disseminating the results of biomedical research in our lifetime. "

Sir Paul Nurse, Cancer Research UK

Your research papers will be:

- available free of charge to the entire biomedical community

- peer reviewed and published immediately upon acceptance

- cited in PubMed and archived on PubMed Central

- yours - you keep the copyright
BioMedcentral 